\title{
Modification of nanoelectrode ensembles by thiols and disulfides to prevent non specific adsorption of proteins
}

\author{
M. Silvestrini ${ }^{a}$, P. Schiavuta ${ }^{b}$, P. Scopece ${ }^{b}$, G. Pecchielan ${ }^{a}$, L.M. Moretto $^{a},{\text { P. } \text { Ugo }^{\mathrm{a}, *}}^{*}$ \\ a Department of Molecular Sciences and Nanosystems, University Ca' Foscari of Venice, Santa Marta 2137, 30123 Venice, Italy \\ ${ }^{\mathrm{b}}$ Associazione CIVEN, via delle Industrie 5, 30175 Marghera - Venice, Italy
}

\section{A R T I C L E I N F O}

\section{Article history:}

Received 13 January 2011

Received in revised form 10 June 2011

Accepted 11 June 2011

Available online 17 June 2011

\section{Keywords:}

Nanoelectrodes

Ensemble

Self-assembled monolayers

Protein

Modified electrodes

\begin{abstract}
A B S T R A C T
The possibility to functionalize selectively with thiols or disulfides the surface of the gold nanoelectrodes of polycarbonate templated nanoelectrode ensembles (NEEs) is studied. It is shown that the Au nanoelectrodes can be coated by a self assembled monolayer (SAM) of thioctic acid (TA) or 2mercaptoethanesulfonic (MES) acid. The study of the electrochemical behavior of SAM-modified NEEs by cyclic voltammetry (CV) at different solution $\mathrm{pH}$, using ferrocenecarboxylate as an anionic redox probe $\left(\mathrm{FcCOO}^{-}\right)$and (ferrocenylmethyl)trimethylammonium $\left(\mathrm{FA}^{+}\right)$as a cationic redox probe, demonstrate that the SAM-modified nanoelectrodes are permselective, in that only cationic or neutral probes can access the SAM-coated nanoelectrode surface. CV, AFM and FTIR-ATR data indicate that proteins such as casein or bovine serum albumin, which are polyanionic at $\mathrm{pH} 7$, adsorb on the surface of NEEs untreated with thiols, tending to block the electron transfer of the ferrocenyl redox probes. On the contrary, the pretreatment of the NEE with an anionic SAM protects the nanoelectrodes from protein fouling, allowing the detection of well shaped voltammetric patterns for the redox probe. Experimental results indicate that, in the case of MES treated NEEs, the protein is bound only onto the polycarbonate surface which surrounds the nanoelectrodes, while the tips of the gold nanoelectrodes remain protein free.
\end{abstract}

(c) 2011 Elsevier Ltd. All rights reserved.

\section{Introduction}

The nanoelectrode ensembles (NEEs), introduced by Chuck Martin's group in the mid nineties [1], have shown properties useful for many advanced applications. In the electroanalytical and sensor fields, NEEs are particularly attractive since they are characterized by highly improved signal-to-background current ratios and extremely low detection limits [1-4], they are suitable to extreme miniaturization [3], can be turned into 3-D nanoelectrode systems [5-8] or can be developed in groups of singly addressable arrays for multianalyte detection $[9,10]$. Thanks to these properties, NEEs are finding numerous applications in different fields, from the biomedical to the energy field, as described in some recent reviews $[11,12]$. It is interesting to note that NEEs are indeed nanocomposite made by a pre-ordered arrangement of two different materials. On one side, there is the large surface of the templating membrane composed by an insulating organic polymer, typically track-etch polycarbonate (PC) $[1,13]$. On the other side, each pore of the starting membrane in the final NEE hosts a gold nanowire, suitable for electrochemical transduction. This duality in the structure of the NEEs surface was recently exploited in our laboratory to immobilize

\footnotetext{
* Corresponding author.

E-mail address: ugo@unive.it (P. Ugo).
}

an antibody-based biorecognition layer onto the wide polycarbonate surface which surrounds the nanoelectrodes [14,15]. This allowed the preparation of an electrochemical immunosensor able to detect the receptor protein HER2, captured selectively by the monoclonal antibody Herceptin ${ }^{\mathrm{TM}}$ bound on the polycarbonate surface. It was shown that for the Herceptin ${ }^{\mathrm{TM}}$ case, the immobilization of the antibody did not hinder the electron transfer at the nanoelectrodes, thanks to the fact that this protein is characterized by a high isoelectric point ( $\mathrm{p} I=9.2)$ [16] which helps in avoiding its adsorption on the gold surface. This is not necessarily the case for negatively charged polypeptides, that is for proteins with low $\mathrm{p} I$, which are known to easily adsorb on gold. Several procedures have been indeed developed to prevent undesired protein adsorption on gold $[17,18]$ as well as on other materials [19]. Note that, in the case of NEE-based biosensors, unwanted protein adsorption could constitute a problem for extending their use to the analysis of complex samples.

Pioneering studies developed on flat gold surfaces and microelectrodes [20-23] showed the possibility to modify electrode surfaces and to tune their ionic selectivity by using self-assembled monolayers (SAM) of thiols with carboxylate functionalities; indeed, by changing the solution $\mathrm{pH}$ it is possible to change the ionic charge of the monolayer. In the present research, we demonstrate the possibility to use SAMs of thiols and disulfides to furnish ionic permselectivity even to the surface of gold nanoelectrodes 

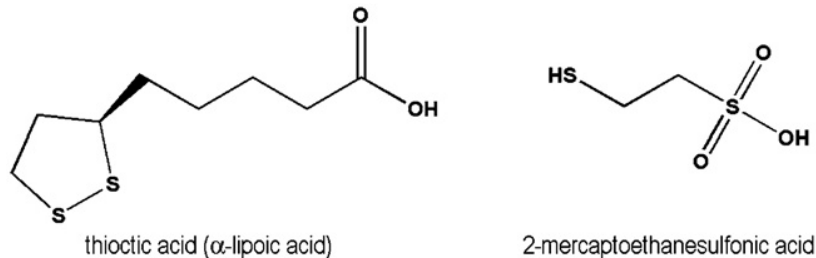

2-mercaptoethanesulfonic acid

Scheme 1. Structural formula of the thiol derivatives used.

with diameter as small as $30 \mathrm{~nm}$. In particular, in the present study we report for the first time on the modification of NEEs by self assembly of the cyclic disulfide thioctic acid (TA) and of the thiol 2-mercaptoethanesulfonic (MES) acid (Scheme 1).

As said above, the majority of proteins adsorbable on gold are polyanionic at physiological $\mathrm{pH}$, therefore, we focused on Au-SAMs formed by negatively charged sulphur compounds which could hinder such undesired protein adsorption. Note that TA is a weak acid, whose carboxylic group is characterized by a $\mathrm{p} K_{\mathrm{a}}$ of 5.4 [24], therefore it is dissociated in neutral or basic solution while at low $\mathrm{pH}$ it is protonated, even when deposited as a SAM on Au [20]. On the other hand, MES is a strong acid whose sulphonic group is always deprotonated (anionic).

Moreover, we bring such a surface modification to a further goal, that is to generate on the NEEs more complex structures which exploit also the affinity of PC for proteins to create on the polymer membrane a protein layer which surrounds, but does not block the nanoelectrodes. The proteins studied to this aim are the globular proteins casein and bovine serum albumin (BSA), which present well known fouling properties with respect to gold surfaces and polycarbonate as well $[25,26]$. We demonstrate here the possibility to obtain on the NEE a complex structure in which the polycarbonate is coated by a sort of protein cushion (on which other biomolecules can be eventually bound), among which the nanoelectrodes, protected by suitable SAMs, remain free to act as efficient electrochemical transducers.

\section{Experimental}

\subsection{Electrochemical apparatus}

All electrochemical measurements were carried out at room temperature with a $\mathrm{CH660A}$ potentiostat controlled via personal computer by its own software, using a three-electrode singlecompartment cell equipped with a platinum counter electrode and an $\mathrm{Ag} / \mathrm{AgCl}$ ( $\mathrm{KCl}$ saturated) reference electrode, to which all reported potential values are referred.

\subsection{FTIR-ATR (attenuated total reflection)}

The spectra were recorded by a Thermo Scientific Smart iTR equipped with a $\mathrm{ZnSe}$ crystal. The resolution of the instrument was adjusted to $4.0 \mathrm{~cm}^{-1}$ and every spectrum was collected with 64 scans.

\subsection{AFM (atomic force microscopy)}

AFM measurements were performed in air on samples dried at room conditions, using a Veeco NS IV Dimension 3100 Scanning Probe Microscope. Images were collected in Tapping mode $\mathrm{T}^{\mathrm{TM}}$ using standard silicon cantilevers with typical resonant frequency $150 \mathrm{kHz}$, elastic constant $5 \mathrm{~N} / \mathrm{m}$. Tip curvature radius was $10 \mathrm{~nm}$, length $6 \mu \mathrm{m}$, conical angle $22^{\circ}$. All the measurements were performed on NEEs fabricated with track-etched polycarbonate membranes with pores diameter of $80 \mathrm{~nm}$. Preliminary electro- static force measurements (EFMs) were performed with the same apparatus, but using cantilever tips metalized with a $20 \mathrm{~nm}$ Pt layer and applying a difference in potential of $20 \mathrm{~V}$ between the tip and the sample.

\subsection{Materials}

Thioctic acid 98\% and ferrocenecarboxylic acid (FcCOOH) 97\% were purchased from Aldrich; $3 \mathrm{M}$ MES solution in water was from Sigma. The salt (ferrocenylmethyl) trimethylammonium hexafluorophosphate $\left(\mathrm{FA}^{+} \mathrm{PF}_{6}{ }^{-}\right)$was prepared by metathesis of the (ferrocenylmethyl) trimethylammonium iodide (Alfa Aesar) with potassium hexafluorophosphate 99\% (Alfa Aesar). Casein was from VWR International and was dissolved $(4 \mathrm{mM})$ in $1 \mathrm{M}$ maleic acid buffer. BSA was purchased from Sigma. Purified water was obtained using Milli-Ro plus Milli-Q (Millipore) water purification system. All other chemicals were reagent grade. Track-etch polycarbonate (PC) membrane filters, thickness $6 \mu \mathrm{m}$, were obtained from SPIpore $^{\mathrm{TM}}$ with nominal pore diameter of $30 \mathrm{~nm}$ or $80 \mathrm{~nm}$, average pore density $6 \times 10^{8}$ pores $\mathrm{cm}^{-2}$, coated with polyvinylpyrrolidone (PVP) by the producer.

\subsection{Template fabrication of NEEs}

Polycarbonate membranes with 30 or $80 \mathrm{~nm}$ pore diameters were used for preparing NEEs used for CV and AFM characterization, respectively.

Ensembles of gold nanoelectrodes were prepared as previously described [7]. Briefly, after wetting for $2 \mathrm{~h}$ in methanol, the track-etched polycarbonate membrane was sensitized into $0.026 \mathrm{M}$ $\mathrm{SnCl}_{2}, 0.07 \mathrm{M}$ trifluoroacetic acid in 50\% methanol in water, for $45 \mathrm{~min}$. After rinsing in methanol, the membrane was dipped in $0.029 \mathrm{M} \mathrm{Ag}\left[\left(\mathrm{NH}_{3}\right)_{2}\right] \mathrm{NO}_{3}$ for $10 \mathrm{~min}$. The membrane was rinsed in methanol and then in water and successively was immersed into the Au plating bath containing $7.9 \times 10^{-3} \mathrm{M} \mathrm{Na}_{3} \mathrm{Au}\left(\mathrm{SO}_{3}\right)_{2}$ in $0.127 \mathrm{M} \mathrm{Na}_{2} \mathrm{SO}_{3}$, at $0^{\circ} \mathrm{C}$. After $30 \mathrm{~min}, 0.625 \mathrm{M}$ formaldehyde was added to the bath. Electroless deposition was allowed to proceed for $15 \mathrm{~h}$, after which additional $0.625 \mathrm{M}$ formaldehyde was added. After a total of $24 \mathrm{~h}$ of plating, the golden membrane was rinsed with water and immersed for $6 \mathrm{~h}$ in $10 \% \mathrm{HNO}_{3}$, then rinsed again with water and dried.

Handy NEEs were assembled as previously described [13]. Briefly: a small piece (approximately $8 \mathrm{~mm} \times 8 \mathrm{~mm}$ ) of golden membrane was attached to a suitable conductive substrate; the gold layer on the outer face of the membrane was removed by peeling with scotch tape (so that only the head of the gold nanowires inside the pores will be exposed to the sample solution); all the surface of the NEE, apart a hole of $3 \mathrm{~mm}$ diameter (which defines the geometric area of the ensemble, $A_{\text {geom }}=0.07 \mathrm{~cm}^{2}$ ), was insulated with a film of plastics (Monokote by Topflite). Good sealing between the nanoelectrodes and the polycarbonate was assured by heating the NEE at $150^{\circ} \mathrm{C}$ for $15 \mathrm{~min}$. Note that the calculated active area (surface of the nanoelectrodes) of the NEE with $30 \mathrm{~nm}$ nanodisks diameter (used for the CVs) is $3 \times 10^{-4} \mathrm{~cm}^{2}$. A schematic drawing of a NEE is shown in Fig. 1.

\subsection{NEEs modification}

NEEs coated with a SAM of TA (TA-NEEs) were prepared by overnight dipping in $0.01 \mathrm{M}$ TA in $75 \%$ ethanol in water [27]. This was followed by rinsing with ethanol to remove any unbound molecule. NEEs coated with MES (MES-NEEs) were prepared by overnight dipping in $0.01 \mathrm{M}$ MES water solution, followed by repeated rinsing with water. Both procedures were carried out at room temperature. NEEs treated with casein or BSA (Cas-NEEs and BSA-NEEs, respectively) were obtained by dipping in a stirred solu- 

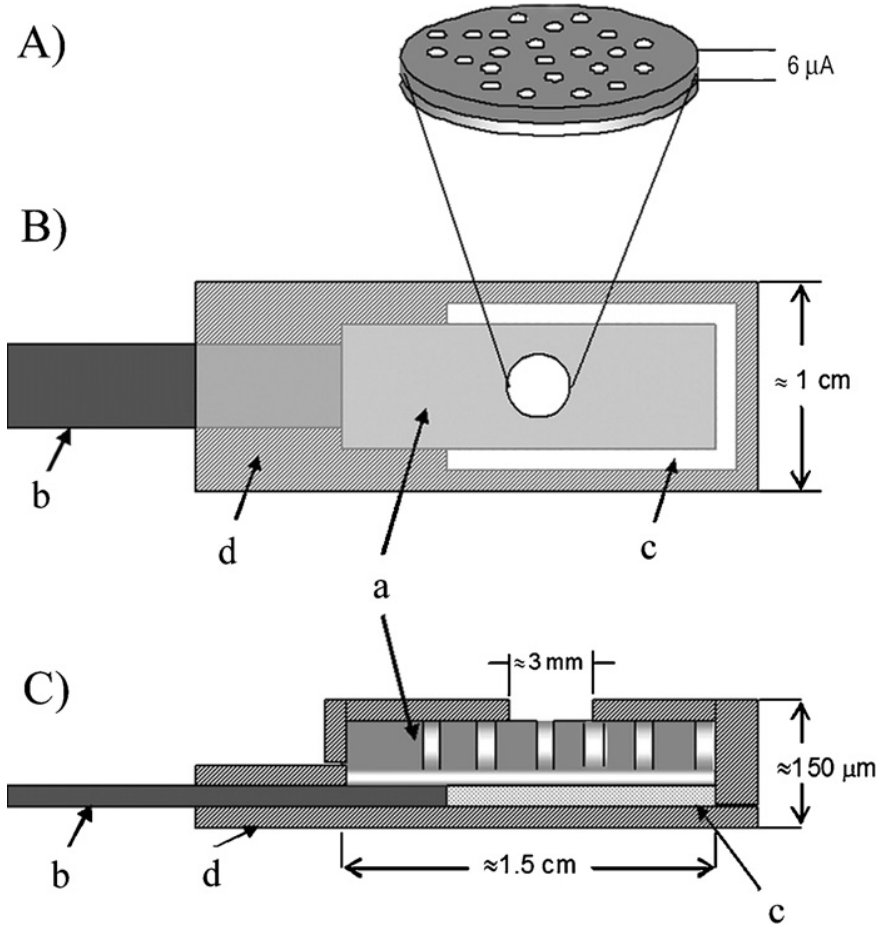

Fig. 1. Scheme of a Au-NEE prepared using a track-etched polycarbonate membrane as template (A). Particular of the section of the active area; (B) top view, (C) section of the all NEE ready for use as working electrode. a: Track-etched golden membrane; b: copper adhesive tape with conductive glue to connect to instrumentation; c: aluminum adhesive foil with non-conductive glue; $d$ : insulating tape. Not all details (namely, the nanoelectrodes dimension) are in scale.

tion of $0.2 \mathrm{mM}$ casein or BSA solution in $0.01 \mathrm{M}$ phosphate buffer $(\mathrm{pH} 7.5)$ for $30 \mathrm{~min}$. The NEEs were repeatedly rinsed with pure phosphate buffer before use. Some NEEs were pre-treated with MES, before the protein treatment, to obtain MES-Cas-NEEs or MES-BSA-NEEs.

In some preliminary experiments, the PVP which impregnates the commercially available track-etched membranes was removed by dipping the membranes in $50 \%(\mathrm{~V} / \mathrm{V})$ acetic acid (HAc) [28].

\section{Results and discussion}

\subsection{Redox probes at SAM modified NEEs}

At first, we studied the effect of TA and MES adsorbed on the surface of the nanoelectrodes by analyzing the cyclic voltammetric behavior of two ferrocene derivatives used as redox probes, that are the cationic probe $\mathrm{FA}^{+}$and the weak acid $\mathrm{FcCOOH}$, which dissociates to the anion $\mathrm{FcCOO}^{-}$in slightly alkaline solutions $\left(\mathrm{p} K_{\mathrm{a}}\right.$ of $\mathrm{FcCOOH}$ is 6.7 in water/methanol [29]). Relevant CV patterns are reported in Figs. 2 and 3, while characteristic potential values, drawn from these CVs, are listed in Table 1.

Fig. 2a shows the comparison of the CVs of $\mathrm{FA}^{+}$in slightly alkaline solution at the bare NEE (full line), TA-NEE (dashed line) and MES-NEE (dotted line). The three patterns practically overlap, showing the characteristics typical of a one-electron reversible oxidation process at a NEE operating under total overlap diffusion conditions [1]. These results indicate that the presence of MES or $\mathrm{TA}$, at $\mathrm{pH} 9$, does not influence the voltammetric behavior of the cationic probe $\mathrm{FA}^{+}$.

For $\mathrm{FcCOO}^{-}$, the peak to peak separation at the bare NEE (see Fig. 2b, full line and Table 1), is slightly larger, suggesting a quasireversible behavior [1]. This can be attributed to the fact that NEEs are very sensitive to kinetics slow-down. Since the first studies on NEEs $[1,30]$, it was indeed demonstrated that these ensembles of nanodisk electrodes behave as electrodes with partially blocked surface [31], for which the true heterogeneous kinetic constant is substituted by an apparent one, the latter being smaller by a factor which corresponds to the fractional electrode area, that is the ratio between active and geometric area $[1,30]$. The validity of such a model was confirmed also by more recent theoretical studies [32-35]. The dashed and dotted lines in Fig. 2b, show that a completely different behavior is observed for $\mathrm{FcCOO}^{-}$at modified NEEs, with the CVs at the TA-NEE (dashed line) and MES-NEE (dotted line) becoming almost featureless.

All these evidences indicate that MES and TA are indeed bound on the gold surface of the nanoelectrodes forming a SAM. On the basis of electrostatic interactions, these SAMs do not affect the electrochemical behavior of the cationic probe $\mathrm{FA}^{+}$while they repel the anionic probe $\mathrm{FcCOO}^{-}$.

Fig. 3 shows the CVs recorded with the same NEEs and with the same redox probes of Fig. 2, but in acidic solutions, namely in $10^{-2} \mathrm{M} \mathrm{HCl}$. At the MES-NEE (dotted line in Fig. 3a) the CV of $\mathrm{FA}^{+}$ does not change significantly from the one recorded in neutral (not shown) or slightly alkaline solution (see Fig. 2a) or at the bare-NEE (full line), while at the TA-NEE (dashed line) only a broad voltammetric signal is recorded. At $\mathrm{pH} 2$ the carboxylic groups of the thioctic acid are protonated, therefore the TA layer is neutral and produces an insulating coating which hinders the electron transfer.

For FcCOOH (see Fig. 3b) a significant suppression of the signal is observed at the TA-NEE (dashed line), while the voltammetric features typical of a one electron-oxidation are detected at the MES-NEE (dotted line) and bare NEE (full line). Note that the protonation of $\mathrm{FCCOOH}$ at $\mathrm{pH} 2$ reflects in a shift of $E_{1 / 2}$ to more positive potential values (see 3rd column in Table 1 ).

The explanation for the voltammetric behavior of $\mathrm{FcCOOH}$ at the TA-NEE is analogue to that for $\mathrm{FA}^{+}$: the SAM of TA is neutral and generates an insulating layer on the surface of the nanoelectrodes. In the case of the MES-NEE, a well resolved CV signal is detected also for $\mathrm{FcCOOH}$ due to the fact that at $\mathrm{pH} 2$ the carboxylic group of the ferrocene derivative is protonated; the probe is neutral and it is no more repelled by the negatively charged MES layer.

All these results indicate that SAMs of suitable sulphur compounds give ionic charge selectivity to NEEs, furnishing to the nanoelectrodes the same permselectivity demonstrated previously for the case of individual $\mu \mathrm{m}$-sized electrodes [20-23]. A MES layer allows only cationic or neutral probes to access the nanoelectrode surface to undergo successful electron transfer. Note that, for TA the selectivity is $\mathrm{pH}$ dependent while for MES this property is $\mathrm{pH}$ independent; for this reason, in the following part of the study, we focused on MES.

\subsection{Voltammetry at protein treated NEEs}

Previous studies [26,36] reported that PVP, which impregnates the commercially available PC membranes, can somehow inhibit the adsorption of proteins on the polymer, even if such an adsorption is not completely prevented [37]. For this reason we performed some preliminary experiments comparing BSA and Cas adsorption on PVP coated vs. PVP-free PC membranes. In the latter case, PVP was removed from commercially available membranes by HAc treatment (see Section 2). The amount of protein adsorbed was estimated by comparing the intensity of the color developed by staining with Fuchsin acid [38] and Naphthol blue black [39]. It was observed that the protein adsorption is slightly higher in the membranes treated with HAc, however this adsorption was not negligible on the untreated commercial membranes. On the basis of this result and taking into account that we are interested in 
a

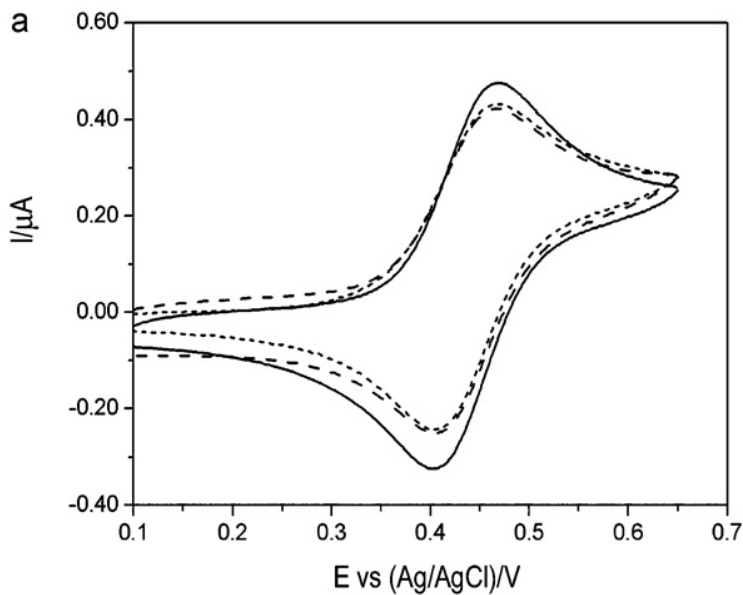

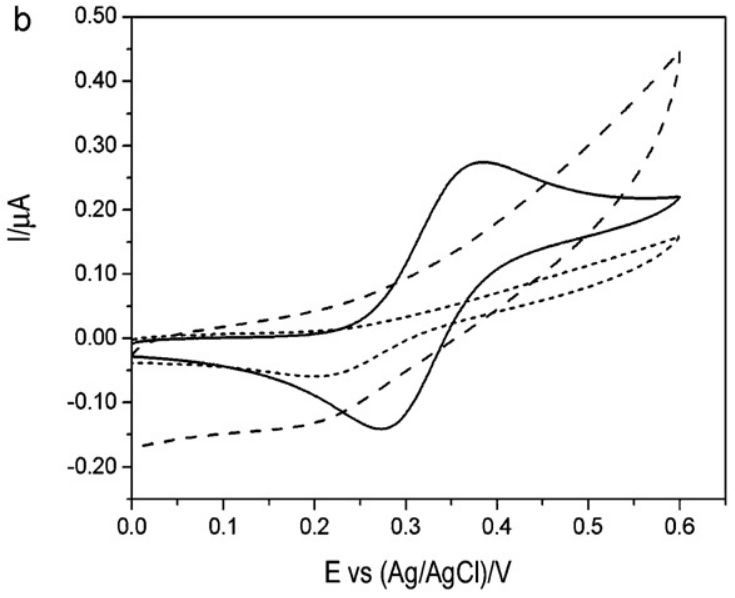

Fig. 2. Cyclic voltammograms in $10^{-2} \mathrm{M}$ carbonate buffer, $\mathrm{pH} 9.0$, of $1.0 \times 10^{-4} \mathrm{M} \mathrm{FA}^{+} \mathrm{PF}_{6}$ (a) and $0.7 \times 10^{-4} \mathrm{M}$ FcCOOH (b), with a bare NEE (full lines), a TA-NEE (dashed lines) and a MES-NEE (dotted lines). Scan rate $20 \mathrm{mV} \mathrm{s}^{-1}$.
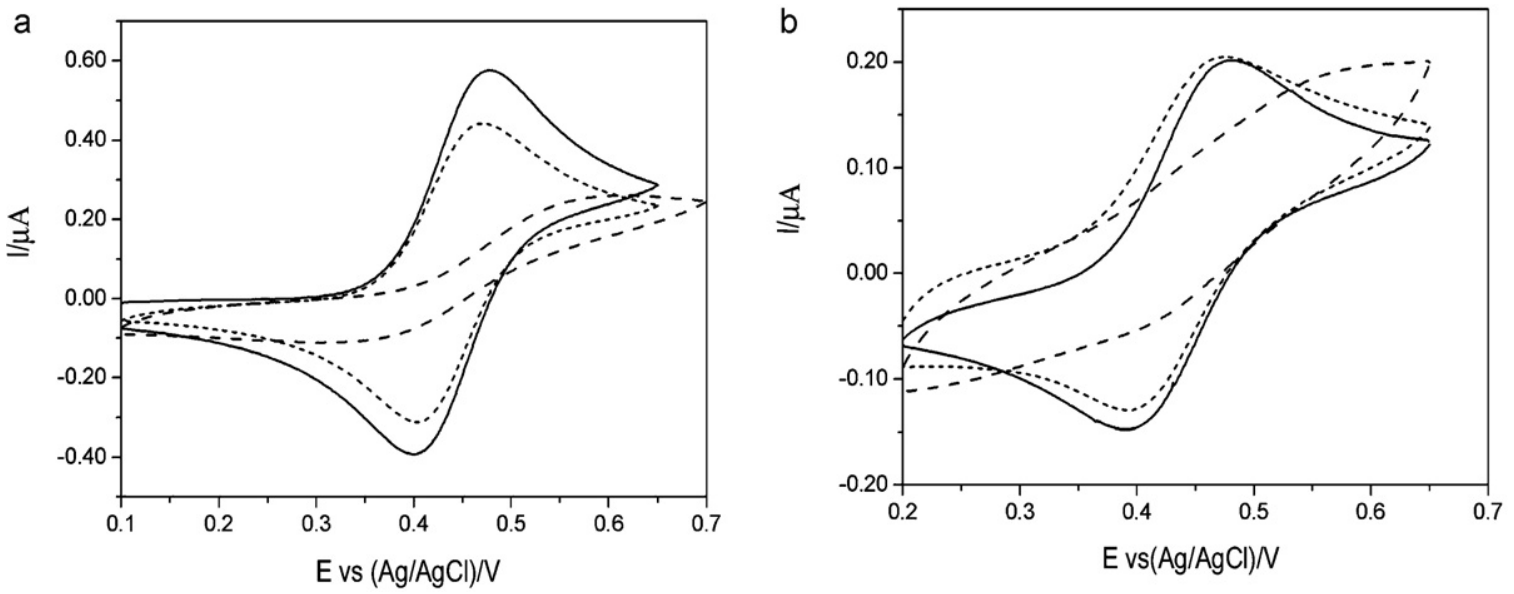

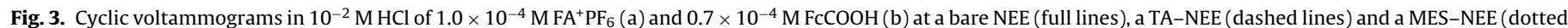
lines). Scan rate $20 \mathrm{mV} \mathrm{s}^{-1}$.

studying the behavior of modified NEEs prepared from as-received commercially available membranes, in the following part of the research we focused on NEEs obtained using PVP-coated PC tracketched membranes.

Fig. 4 compares the voltammetric behavior of the redox probe $\mathrm{FA}^{+}$at a bare NEE (full line), a Cas-NEE (casein treated, not thiolated; dashed line) and a MES-Cas-NEE (MES and casein treated; dotted line).

Heavy distortion and degradation of the CV pattern is indeed observed at the Cas-NEE. The capacitive current, estimated as the difference in the forward to backward CV pattern [40] before the upraise of the voltammetric peak (e.g., at $0.2 \mathrm{~V}$ ), increases dramatically. With respect to the bare NEE, the peak signal for $\mathrm{FA}^{+}$becomes broader and less resolved from the background. Moreover, a significant ohmic drop contribution is observed, which causes the sloping of all the CV pattern. These evidences suggest that casein is strongly adsorbed on all the surface of the NEE, forming a blocking layer which hinders the electron transfer at the surface of the Au nanoelectrodes. Similar characteristics were observed at BSA-NEEs (not shown).

The adsorption of the proteins was studied also by FTIR-ATR measurements performed on NEEs, before and after treatment with casein.

The gray-line spectrum in Fig. 5 shows the IR absorption features typical of bisphenol-A polycarbonate [41]. The spectra of the Cas-NEE (Fig. 5, black-line) and BSA-NEE (not shown) present additional absorption peaks which are indicative of the presence of a protein layer; they are: the broad absorption system in the $3100-3600 \mathrm{~cm}^{-1}$ range, due to $\mathrm{N}-\mathrm{H}$ stretching with superimposed the absorption bands typical for residual water; the peaks at $1730 \mathrm{~cm}^{-1}, 1640 \mathrm{~cm}^{-1}$ and $1590 \mathrm{~cm}^{-1}$ which correspond to the amides I, II and III absorption peaks, respectively. Our results are

Table 1

Characteristic potential values relevant to the cyclic voltammograms in Figs. 2 and 3.

\begin{tabular}{|c|c|c|c|c|c|c|c|}
\hline \multirow[t]{2}{*}{$\mathrm{pH}$} & \multirow[t]{2}{*}{ Analyte } & \multicolumn{2}{|l|}{ Bare NEE } & \multicolumn{2}{|l|}{ TA-NEE } & \multicolumn{2}{|l|}{ MES-NEE } \\
\hline & & $E_{1 / 2}(\mathrm{~V}$ vs. $\mathrm{Ag} / \mathrm{AgCl})$ & $\Delta E_{\mathrm{p}}(\mathrm{V})$ & $E_{1 / 2}(\mathrm{~V}$ vs. $\mathrm{Ag} / \mathrm{AgCl})$ & $\Delta E_{\mathrm{p}}(\mathrm{V})$ & $E_{1 / 2}(\mathrm{~V}$ vs. $\mathrm{Ag} / \mathrm{AgCl})$ & $\Delta E_{\mathrm{p}}(\mathrm{V})$ \\
\hline \multirow[t]{2}{*}{9} & $\mathrm{FA}^{+}$ & 0.440 & 0.060 & 0.440 & \multirow[t]{4}{*}{0.060} & 0.440 & 0.060 \\
\hline & $\mathrm{FcCOO}^{-}$ & 0.330 & 0.090 & No peaks & & \multicolumn{2}{|c|}{ Only a small reduction peak at $0.20 \mathrm{~V}$} \\
\hline \multirow[t]{2}{*}{2} & $\mathrm{FA}^{+}$ & 0.440 & 0.070 & Broad peaks & & 0.440 & 0.070 \\
\hline & $\mathrm{FcCOOH}$ & 0.430 & 0.090 & No peaks & & 0.430 & 0.090 \\
\hline
\end{tabular}




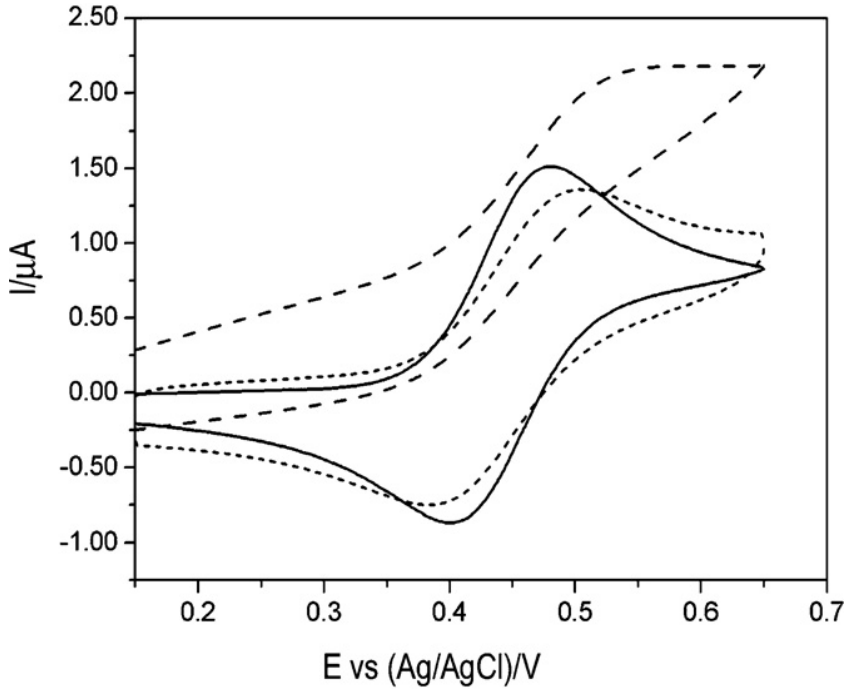

Fig. 4. Cyclic voltammograms recorded in $5 \times 10^{-4} \mathrm{M} \mathrm{FA}^{+}, 0.01 \mathrm{M}$ phosphate buffer pH 7.5 with a bare NEE (full line), a Cas-NEE (dashed line) and a MES-Cas-NEE (dotted line). Scan rate $20 \mathrm{mV} \mathrm{s}^{-1}$.

comparable with those obtained by Kim et al. [41] for BSA adsorbed on virgin PC. The evidence that spectra recorded on NEEs and virgin PC displays the same features excludes any key-role for the adsorption of the protein related to the presence or absence of the gold nanoelectrodes.

The dotted line in Fig. 4 shows the $\mathrm{CV}$ recorded in $\mathrm{FA}^{+}$ at a MES-Cas-NEE, that is a NEE in which the nanoelectrodes were coated with MES before being dipped in the casein solution. The comparison with the signal at the Cas-NEE with no previously adsorbed SAM, indicates that MES protects efficiently the nanoelectrodes from the adsorption of the protein, allowing one to record perfectly reversible signals for $\mathrm{FA}^{+}$oxidation even after treating the NEE with the protein solution. Fully comparable results were obtained for BSA (not shown).

\subsection{AFM characterization of NEEs}

In order to investigate the morphology of the NEEs treated with MES and proteins, AFM characterizations were performed. The topography of a bare NEE prepared with track etched PC, with pores of $80 \mathrm{~nm}$ nominal diameter, is shown on the left side in Fig. 6a. The dark spots, of approximately $120 \mathrm{~nm}$ diameter, corre-

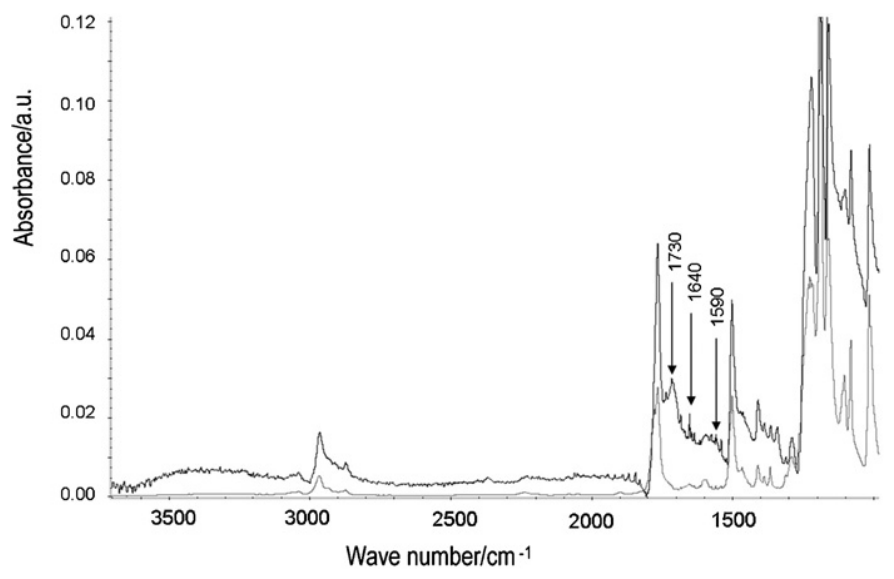

Fig. 5. FTIR-ATR spectra of a bare NEE (gray-line) and a Cas-NEE (black-line). spond to the nanoelectrodes, while the middle-toned flat surface corresponds to the surrounding PC. This image as well as the profile on the right (taken in correspondence of the white line on the topographic image), confirm that the majority of the pores are filled with nanowires. In particular, the profile shows that the heads of the wires are slightly recessed with respect to the outer surface of the membrane; for instance, the nanoelectrode in position around $0.10 \mu \mathrm{m}$ is approximately $30-40 \mathrm{~nm}$ recessed, while the nanoelectrode in position $2.00 \mu \mathrm{m}$ is approximately $20 \mathrm{~nm}$ recessed. Note that AFM profiles of virgin track-etched polycarbonate membranes (not shown) demonstrate that the cantilever penetrates into the empty pores up to a depth of $100 \mathrm{~nm}$, which corresponds to the maximum depth accessible with the cantilever tips used here. Preliminary electrostatic force measurements (not shown) gave large electrical conductivity values only in correspondence of the position of the dark spots in Fig. 6a, so confirming that the pores are now filled with metal nanowires. The number of nanoelectrodes per unit area (surface density) was evaluated by counting the dark spots detected in a square $10 \mu \mathrm{m} \times 10 \mu \mathrm{m}$ in the AFM and EFM topographic images; the measured surface density matches with the nominal pore density declared by the producer that is $6 \times 10^{8}$ pores (or nanoelectrodes) $\mathrm{cm}^{-2}$. The average diameter of the nanoelectrodes, drawn from the AFM data, results slightly larger (approximately $120 \mathrm{~nm}$ ) than the nominal diameter of the pores $(80 \mathrm{~nm})$. All these results agree with previous detailed studies performed by using a variety of electron microscopies [42,43] which demonstrated that, by performing gold deposition under the experimental conditions used here, the majority of the pores are indeed filled with gold and that the obtained nanoelectrodes have diameters slightly larger than the nominal values of the pores. The slight recession observed for the gold NEEs is probably due to the procedure used to clean the NEEs from the outer deposit of gold by peeling with scotch tape [1]. This agrees with previously reported evidences that the peeling of the NEE surface can break the very end of the gold nanowires; on one side Martin and co-workers showed this by careful FE-SEM analysis [44], on the other side, evidences of a slight recession were gained by the observation of some peculiarities in the electrochemical behavior of NEEs in high viscosity ionic liquids [45], where NEEs operate under pure radial diffusion conditions. It must be emphasized that when NEEs operate in total overlap regime, this slight recession has no final effect on the voltammetric patterns [45].

It should be noted that the same AFM measurements were performed on MES-NEEs, but data did not show relevant differences between not-thiolated vs. thiolated electrodes (not shown), since the SAM is too thin (approximately, $5 \AA$ thick [46]) to be detected.

To study the role of the adsorption of proteins and the efficiency of the protection by SAMs, a bare NEE and a MES-NEE were dipped for $30 \mathrm{~min}$ in a solution containing BSA. The obtained samples, named BSA-NEE and MES-BSA-NEE, respectively, were then analyzed by AFM and relevant results are shown in Fig. $6 \mathrm{~b}$ and $\mathrm{c}$, respectively.

The topography and profilometric pattern of the BSA-NEE (Fig. 6b) show that the protein molecules coat almost all the surface of the unthiolated NEE so causing an increase of the roughness of the outer surface. Only few nanoelectrodes (dark spots) can now be distinguished (such as those, for instance, at positions $0.00,1.65$ and $1.80 \mu \mathrm{m}$ in the profile).

Fig. $6 \mathrm{c}$ shows that the situation changes dramatically for the MES-BSA-NEE. The topographic image demonstrates that, even after prolonged contact with the BSA solution, the thiolated nanoelectrodes remain free and their tips are clearly distinguishable from the surroundings. The roughness of the profile is still higher than in Fig. 6a (bare NEE), however, the height of the step which corresponds to the spatial transition between each nanoelectrode 

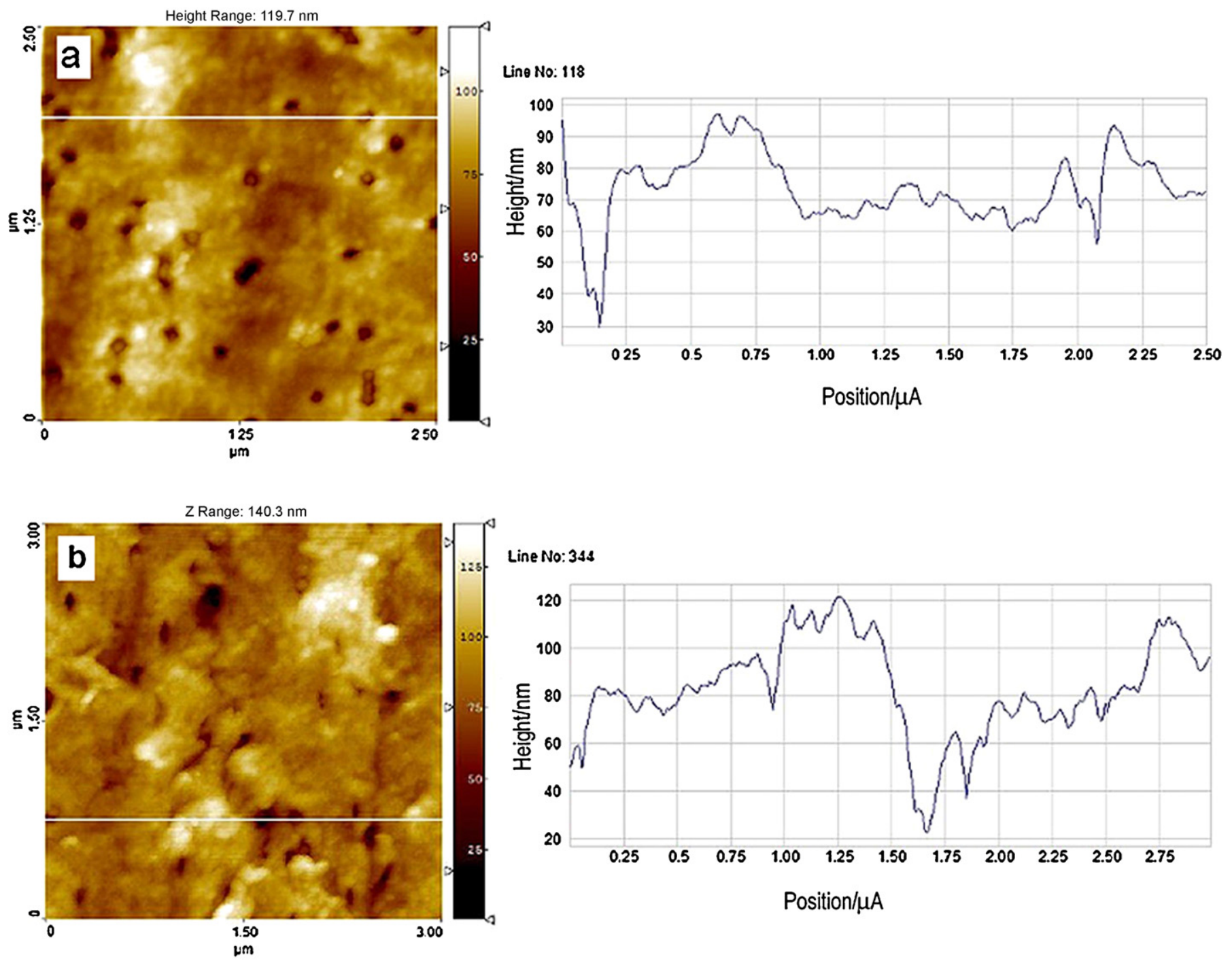

Line No: 344
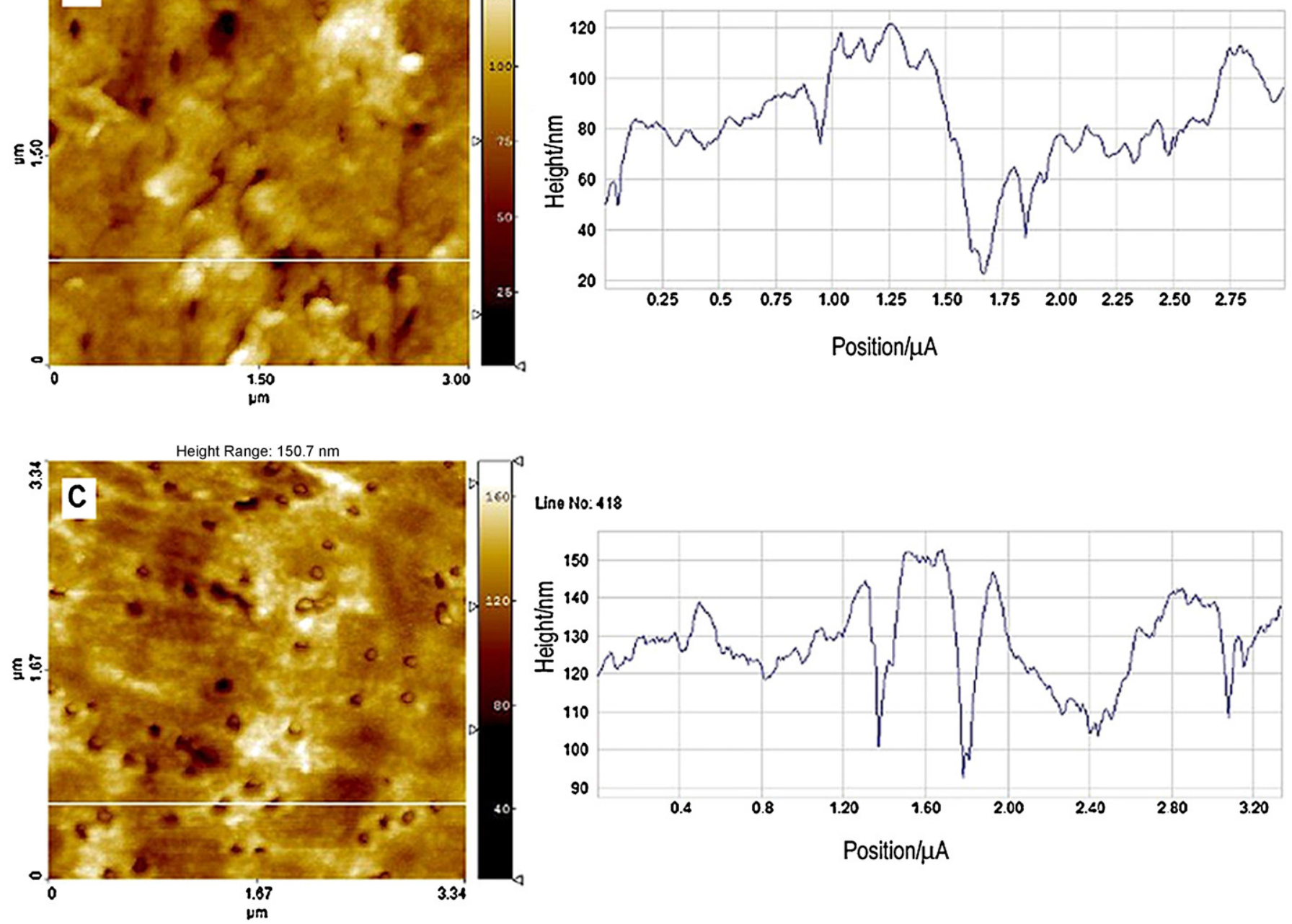

Line No: 418

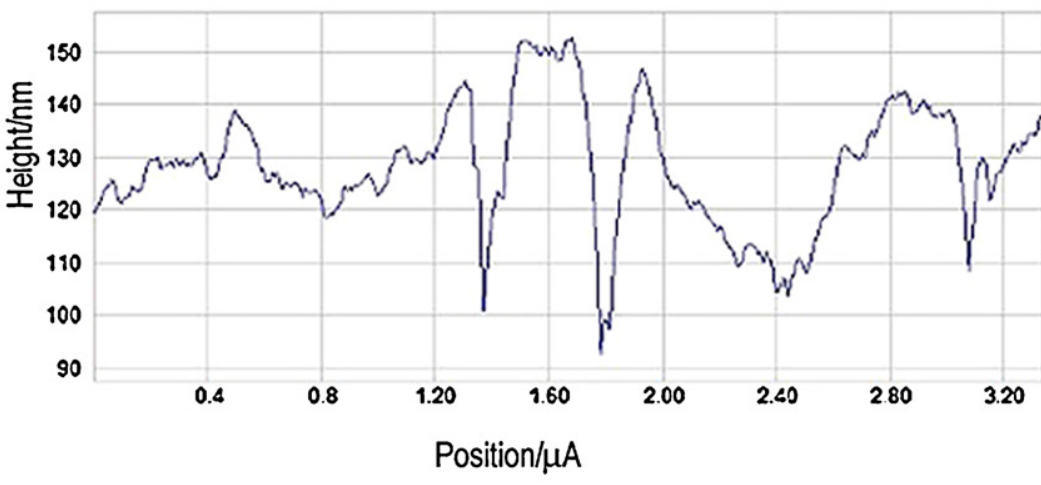

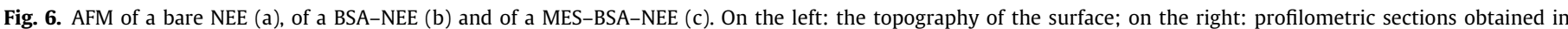
correspondence of the white lines shown in the topographic images.

and the surrounding insulator, increases, being now approximately double than the height of the steps reported in Fig. 6a. In the profile on the right of Fig. 6c, the steps for the two nanoelectrodes in position 1.40 and $1.80 \mu \mathrm{m}$ are now $50-60 \mathrm{~nm}$ high. All these evidences indicate that a protein layer is adsorbed on the MES-BSA-NEE, but it coats only the PC, while the thiolated nanoelectrodes are protein free. These observations fully match with the voltammetric evidences reported in the previous section. 


\section{Conclusions}

The results here reported confirm the effectiveness of SAM of TA and MES to functionalize the gold surface of the very small nanoelectrodes that compose a NEE. This is useful, on one side, for protecting the Au nanoelectrode from undesired adsorption of proteins so avoiding interferences in the transduction of electrochemical signal. Note that, de-protection of the Au nanoelectrodes surface by electrochemical desorption of SAMs is, in principle, possible by performing the cathodic stripping of the SAM $[47,48]$. On the other hand, the present results open the way to the selective functionalization of NEEs, which can be performed by arranging different chemical functionalities on the gold of the nanoelectrodes vs. the organic surface of the polycarbonate. In the examples shown here, the final result of the modification of NEEs with MES and proteins can be imaged as a sort of protein cushion deposited on the PC with the SAM-coated gold nanoelectrodes remaining protein free. To the best of our knowledge, this is the first report showing the possibility to exploit NEEs for the controlled building of such a protein-thiols interconnected structure.

\section{Acknowledgments}

This work was supported financially by MIUR (Rome), project: PRIN 2008MWHCO2.

M.S. is the grateful recipient of a grant by Regione Veneto-FSE.

We thank prof. Justin Gooding (The University of New South Wales, Sydney, Australia) for helpful discussion and suggestions, and prof. Renzo Ganzerla (University Ca' Foscari) for the FTIR-ATR measurements.

\section{References}

[1] V.P. Menon, C. Martin, Anal. Chem. 67 (1995) 1920.

[2] P. Ugo, L.M. Moretto, S. Bellomi, V.P. Menon, C.R. Martin, Anal. Chem. 68 (1996) 4160.

[3] L.M. Moretto, N. Pepe, P. Ugo, Talanta 62 (2004) 1055

[4] F.C. Pereira, L.M. Moretto, M. De Leo, M.V. Boldrin Zanoni, P. Ugo, Anal. Chim. Acta 575 (2006) 16.

[5] R. Gasparac, B.J. Taft, M.A. Lapierre-Devlin, A.D. Lazareck, J.M. Xu, S.O. Kelley, J. Am. Chem. Soc. 126 (2004) 12270.

[6] K. Krishnamoorthy, C.G. Zoski, Anal. Chem. 77 (2005) 5068.

[7] M. De Leo, A. Kuhn, P. Ugo, Electroanalysis 19 (2007) 227.

[8] L.X. Cao, P.S. Yan, K. Sun, D.W. Kirk, Electroanalysis 21 (2009) 1183.
[9] C.G.Zoski, N. Yang, P. He, L. Bernardini, M. Koudelka-Hep, Anal. Chem. 79 (2007) 1474.

[10] L. Soleymani, Z. Fang, E.H. Sargent, S.O. Kelley, Nat. Nanotechnol. 4 (2009) 844

[11] J.I. Yeh, H. Shi, Nanomed. Nanobiotechnol. 2 (2010) 176.

[12] P. Ugo, L.M. Moretto, B. Scrosati, in: J. Garche, C. Dyer, P. Moseley, Z. Ogumi, D. Rand, B. Scrosati (Eds.), Encyclopedia of Electrochemical Power Sources, vol. 2, Elsevier, Amsterdam, 2009, p. 92.

[13] P. Ugo, L.M. Moretto, in: C.G. Zoski (Ed.), Handbook of Electrochemistry, 1st edn., Elsevier, Amsterdam, 2007 (Chapter 16.2).

[14] S. Pozzi Mucelli, M. Zamuner, M. Tormen, G. Stanta, P. Ugo, Biosens. Bioelectron. 23 (2008) 1900

[15] M. Zamuner, S. Pozzi Mucelli, M. Tormen, G. Stanta, P. Ugo, Eur. J. Nanomed. 1 (2008) 33.

[16] H. Wiig, C.C. Gyenge, O. Tenstad, J. Physiol. 567 (2005) 557.

[17] S. Yu, S.B. Lee, M. Kang, C.R. Martin, Nano Lett. 1 (2001) 495.

[18] S. Yu, S.B. Lee, C.R. Martin, Anal. Chem. 75 (2003) 1239.

[19] C.C.A. Ng, S. Ciampi, J.B. Harper, J.J. Gooding, Surf. Sci. 604 (2010) 1388.

[20] Q. Cheng, A. Brajter-Toth, Anal. Chem. 64 (1992) 1998.

[21] Q. Cheng, A. Brajter-Toth, Anal. Chem. 67 (1995) 2767.

[22] Q. Cheng, A. Brajter-Toth, Anal. Chem. 68 (1996) 4180.

[23] J. Zhao, L. Luo, X. Yang, E. Wang, S. Dong, Electroanalysis 11 (1999) 1108.

[24] M. Windholz, S. Budavari, R.F. Blumetti, E.S. Otterbein, The Merck Index. An Encyclopedia of Chemicals, Drugs, and Biologicals, 10th edn., Merck \& Co., Inc., Rahway, NJ, 1983.

[25] J. Johansson, H.K. Yasuda, R.K. Bajpai, Appl. Biochem. Biotechnol. 70-72 (1998) 747.

[26] M. Henry, C. Dupont-Gillian, P. Bertrand, Langmuir 19 (2003) 6271

[27] E. Chow, D. Ebrahimi, J.J. Gooding, D.B. Hibbert, Analyst 131 (2006) 1051.

[28] I.F. Cheng, C.R. Martin, Anal. Chem. 60 (1988) 2163.

[29] R.A. Benkeser, D. Goggin, G. Schroll, J. Am. Chem. Soc. 76 (1954) 4025

[30] B. Brunetti, P. Ugo, L.M. Moretto, C.R. Martin, J. Electroanal. Chem. 491 (2000)

[31] C. Amatore, J.-M. Saveant, D. Tessier, J. Electroanal. Chem. 147 (1983) 39.

[32] C. Amatore, A.I. Oleinick, I. Svir, Anal. Chem. 81 (2009) 4397.

[33] T.J. Davies, R.G. Compton, J. Electroanal. Chem. 585 (2005) 63.

[34] N. Godino, X. Borrise, F.X. Munoz, F.J. del Campo, R.G. Compton, J. Phys. Chem C 113 (2009) 11119.

[35] J. Guo, E. Lindner, Anal. Chem. 81 (2009) 130

[36] M. Henry, P. Bertrand, Surf. Interface Anal. 41 (2009) 105

[37] S. Robinson, P.A. Williams, Langmuir 18 (2002) 8743.

[38] M.C. Gay, Annales du Lab. de Recerche des Musées de France, 1970, p. 8

[39] E. Martin, Studies in Conservation, vol. 22, 1977, p. 63.

[40] A.J. Bard, L.R. Faulkner, Electrochemical Methods. Fundamentals and Applications, 2nd edn., John Wiley \& Sons, Inc., New York, 2001.

[41] K.J. Kim, A.G. Fane, M. Nystrom, A. Pihlajamaki, J. Membr. Sci. 134 (1997) 199.

[42] P. Ugo, N. Pepe, L.M. Moretto, M. Battagliarin, J. Electroanal. Chem. 560 (2003) 51.

[43] M. De Leo, F.C. Pereira, L.M. Moretto, P. Scopece, S. Polizzi, P. Ugo, Chem. Mater 19 (2007) 5955

[44] S. Yu, N. Li, J. Wharton, C.R. Martin, Nano Lett. 3 (2003) 815.

[45] M. De Leo, L.M. Moretto, O. Buriez, P. Ugo, Electroanalysis 21 (2009) 392.

[46] A. Dalmia, C.C. Liu, R.F. Savinell, J. Electroanal. Chem. 430 (1997) 205.

[47] Y. Dong, S. Abaci, C. Shannon, Langmuir 19 (2003) 8922.

[48] J.J. Calvente, Z. Kovacova, M.D. Sanchez, R. Andreu, W.R. Fawcett, Langmuir 12 (1996) 5696. 